\title{
Preconceito no futebol feminino brasileiro: uma revisão sistemática
}

\author{
Fábio Luís Santos Teixeira* \\ Iraquitan de Oliveira Caminha**
}

\begin{abstract}
Resumo: O objetivo deste estudo é identificar as condições de existência do preconceito de gênero no futebol feminino à luz da literatura científica e discutir os aspectos sócio-culturais que os fundamentam. Realizamos uma busca de artigos em bases de dados utilizando descritores específicos. Registramos uma distribuição dos trabalhos entre três abordagens: histórica, pedagógica e psicossocial. As principais formas de preconceito são a segregação, o cerceamento em determinadas práticas esportivas, erotização da mulher e vigilância sobre a identidade de gênero. Concluise que o preconceito sobre as mulheres é causado pela idéia de incompetência e fragilidade fundadas no discurso das diferenças biológicas.
\end{abstract}

Palavras-chave: Futebol feminino. Preconceito, Identidade de gênero

\section{INTRODUÇÃo}

Nos últimos séculos, a crescente participação da mulher em territórios legitimamente considerados como masculinos tem revelado uma nova dinâmica social caracterizada, especialmente, pela redução das diferenças entre os gêneros (RAGO, 2007, BATISTA; DEVIDE, 2009).

Do espaço privado da casa ao espaço público da convivência social, do trabalho doméstico ao trabalho assalariado, a ampliação dos espaços sociais, conquistados pelas mulheres, se consolidou a partir de resistências e reivindicações que não cessaram de reclamar condições de igualdade em relação ao homem (MARTIN, 2006).

\footnotetext{
'Professor da Universidade Federal de Pernambuco - UFPE e do Instituto Brasileiro de Gestão e Marketing - IBGM, Recife, PE, Brasil. E-mail: fabioesef@hotmail.com

"Professor pesquisador do Departamento de Educação Física (UFPB) e dos Programas de Pós-graduação em Educação Física (UFPB/UPE) e Filosofia (UFPB), João Pessoa, PB, Basil. E-mail: iraqui@uol.com
} 
Tal ampliação, denominada pelos especialistas como movimento de emancipação feminina (RAGO, 2007; GIULANI, 2007), pode ser sentida nos dias de hoje de diversas formas, desde a adoção de estilos de vida muito próximos ao masculino, até a flexibilização nas maneiras como as mulheres lidam com o seu próprio corpo.

No âmbito das práticas corporais, por exemplo, é possível apontar para a inserção cada vez maior da mulher na dimensão do esporte. No caso do futebol, esporte tradicionalmente associado à virilidade e ao esforço físico masculino, tem-se percebido um aumento na participação feminina impulsionada pela realização de competições internacionais como a Copa do mundo de futebol e a inserção do futebol feminino nas Olimpíadas.

O reconhecimento do futebol feminino, no âmbito esportivo mundial, pode ser comprovado pela quantidade de trabalhos científicos que têm sido publicados no sentido de conferir cientificidade ao seu treinamento (SILVA; ROMANO; ROXO, 1999; OLIVEIRA et al., 2006), prever e tratar lesões características (STEWIEN; CAMARGO, 2005), ou melhorar o desempenho de atletas consideradas de elite (QUEIROGA et al., 2008; ALMEIDA; PALMA, 2011).

Não obstante a quantidade de estudos científicos publicados, a expansão do futebol feminino ainda sofre sérios entraves (SOUZA JÚNIOR; DARIDO, 2002). No Brasil, país reconhecido internacionalmente pela qualidade do futebol, o desenvolvimento do futebol feminino obedece a uma lógica intermitente de expansão e refluxo, lógica fundamentada por um sistema de proibições e permissões instaurado desde o século XIX (FRANZINI, 2005). De maneira geral, o futebol feminino parece ser tolerado pela sociedade brasileira, mas ainda não ganhou espaços de visibilidade equivalentes ao futebol masculino, ou mesmo ao futebol feminino em outros países.

Tendo em vista este cenário, a presente pesquisa procura animar uma discussão sobre o preconceito de gênero no futebol feminino, revisando sistematicamente os estudos científicos sobre o tema. Especificamente, procuramos identificar no conjunto de trabalhos 
publicados as condições de existência do preconceito de gênero no contexto no futebol feminino e discutir os aspectos sócio-culturais que as fundamentam. Dirigimos o nosso olhar para o caso do Brasil, tendo em vista a hegemonia masculina evidenciada em seu contexto esportivo e as discrepâncias de gênero em relação à prática do futebol (FRANZINI, 2005).

Nossa hipótese é de que, diferentemente do futebol masculino, o futebol feminino não usufrui das mesmas condições de visibilidade e do mesmo reconhecimento social devido a relações conflituosas de gênero, decorrentes da inserção da mulher no espaço esportivo, culturalmente considerado como masculino (FRANZINI, 2005; GOELLNER, 2003). Por outro lado, o preconceito está vinculado à necessidade de assegurar a reprodução do arquétipo feminino de "maternidade" e "dona do lar" de maneira a impedir, bloquear ou retardar a quebra da hegemonia econômica capitalista que reconhece a divisão binária entre "homem/sexo forte" e "mulher/sexo frágil" como a única legítima aos olhos da sociedade.

A concepção de preconceito que norteia esta reflexão remete às noções de normalidade e anormalidade erigidas pelo filósofo Michel Foucault (2006) no âmbito de suas reflexões sobre a história da sexualidade. Este pensador verifica que, no contexto dos jogos de poder, normalidade e anormalidade se manifestam desempenhando processos de subjetivação os quais definem efeitos de verdade sobre o corpo.

No caso dos efeitos de verdade sobre a sexualidade, o pensador denuncia a existência de um dispositivo da sexualidade surgido a partir da modernidade, que implica na fixação de um sistema binomial de condutas sexuais normais e no estabelecimento de funções econômicas, gestualidades, comportamentos, modos de ser considerados normais e específicos para o sexo masculino e para o sexo feminino. Vale ressaltar ainda que o dispositivo da sexualidade atua de forma compulsória, ou seja, automática e auto-regulada na medida em que a infração de tal dispositivo aciona mecanismos de cerceamento cuja intenção é conter qualquer afastamento das condutas consideradas normais. 
Assim, consideramos que o preconceito se manifesta caso a condição compulsória da sexualidade seja desrespeitada, isto é, quando as expectativas pré-concebidas sobre cada gênero são infringidas, desencadeando mecanismos de supressão e proibição que remetem ao anormal.

Tendo em vista este cenário, acreditamos que esta forma de compreensão do preconceito pode auxiliar no estudo das relações de poder associadas ao desenvolvimento do futebol feminino em nossa sociedade. Tal possibilidade se ratifica, pois, o reconhecimento da condição da mulher no dispositivo da sexualidade pode nos auxiliar na compreensão das posições ocupadas por elas no campo esportivo, condição sem a qual não é possível qualquer tipo de modificação deste quadro. Além disso, o estudo do preconceito na perspectiva apresentada pode desvelar algumas indicações sobre as modificações, reorientações e clivagens complexas do dispositivo da sexualidade na gestão da vida da mulher contemporânea no tocante às práticas corporais esportivas.

Iniciamos demonstrando os aspectos metodológicos do estudo destacando os procedimentos de coleta e análise dos periódicos. Num segundo momento apresentamos os resultados da pesquisa obtidos a partir da análise enunciativa dos escritos. Neste ponto procuramos demonstrar os aspectos que fundamentam o preconceito no futebol feminino articulando com as perspectivas de estudo adotadas em cada artigo analisado. Em seguida realizamos uma discussão sobre as questões que fundamentam o preconceito de gênero no futebol feminino tomando como cenário os três núcleos temáticos mais regulares nos artigos investigados.

\section{Metodologia}

Este estudo qualitativo foi desenvolvido sob a ótica da revisão sistemática, tipo de revisão que permite integrar as informações de um conjunto de estudos científicos realizados separadamente sobre 
um determinado fenômeno ou realidade. A revisão sistemática possibilita a interpretação e identificação de categorias ${ }^{1}$ representativas de uma realidade específica, ou identificar temas que revelam a necessidade de evidências, auxiliando, assim, na orientação para investigações futuras (MULROW, 1994).

Para o desenvolvimento do estudo realizamos uma busca de artigos que obedeceu a duas fases. A primeira fase consistiu na busca de artigos nas bases de dados Bireme, MEDLINE, LILACS, SCIELO, ADOLEC e IBECS utilizando os seguintes descritores e palavras-chave nas línguas inglesa e portuguesa: "futebol feminino", "futebol", "mulher", "preconceito de gênero", "esporte", "mulheres", "estigmatização", "esportes", "preconceito de gênero", "female soccer" e "women soccer". Neste momento os operadores lógicos and e or foram utilizados para identificar artigos não encontrados até o momento.

Para refinar a pesquisa estabelecemos como critérios de inclusão artigos publicados nos últimos 10 anos em periódicos nacionais e internacionais da Educação Física e áreas afins com a temática pertinente aos nossos objetivos. Os critérios de exclusão foram trabalhos publicados em idiomas diferentes do português e do inglês, e teses dissertações, resenhas e artigos de revisão sistemática.

A busca inicial possibilitou a identificação de 732 artigos. Depois da leitura dos títulos e resumos, e de observar os critérios de exclusão ${ }^{2}$, chegamos ao total de 10 artigos. Depois deste momento, percebemos a necessidade de realizar uma segunda fase da coleta que ocorreu por meio de uma busca manual em periódicos nacionais qualificados da Educação Física. Esta segunda fase se justifica pela

\footnotetext{
${ }^{1}$ Segundo Bourdieu (2007), o termo categoria se refere ao parentesco ou ainda àquilo que aparece com maior destaque "publicamente". As categorias podem ser entendidas, também, como elementos semânticos que representam os diversos aspectos que podem determinar a existência de um dado fenômeno.

${ }^{2}$ Foram excluídos os estudos sem resumo/abstract, os estudos que não fazem referência à realidade brasileira e do futebol feminino, as investigações do tipo bibliográfico, estudos de revisão ou que não se caracterizam como de campo e os estudos escritos em outros idiomas diferentes do português, inglês e espanhol.
} 
escassez de resultados obtidos no primeiro momento da coleta, fato que poderia comprometer a investigação. Ao final do processo chegamos a um total de 14 artigos selecionados.

Para analisar o corpus da pesquisa utilizamos a técnica de análise de discurso seguindo a proposta arqueológica foucaultiana. Este tipo de análise favorece a identificação de enunciados que são tipos especiais de discursos capazes de desenvolver função de existência. O termo função de existência não deve ser compreendido como causa original de algum fenômeno, mas como uma função [...] que cruza um domínio de estruturas e de unidades possíveis e que faz com que apareçam, com conteúdos concretos, no tempo e no espaço (FOUCAULT, 2008, p. 98). A análise de enunciados constitui, portanto, uma maneira de abordar as performances verbais isolando os termos que aí se cruzam e de demarcar as suas diversas regularidades num contexto histórico.

Na primeira fase da análise realizamos uma leitura exaustiva dos textos. Em seguida, passamos à fase de identificação de enunciados que consistiu na seleção de trechos referentes às condições de existência do preconceito no futebol feminino. Posteriormente averiguamos se tais trechos desempenham função de enunciado. Para desenvolver esta averiguação construímos uma grelha de análise na qual identificamos o referencial, o sujeito, o campo associado e a materialidade que são os quatro elementos constituintes de um enunciado segundo Foucault (2008). Finalmente, agregamos os enunciados mais regulares de maneira a construir as categorias temáticas discutidas. A seguir apresentamos os resultados da pesquisa.

\section{Resultados e discussão}

Os 15 artigos selecionados encontram-se expostos no quadro a seguir (Quadro 1). Destacamos os autores, o ano de publicação, os objetivos de cada investigação, além da perspectiva de análise adotada, as principais conclusões, e as determinantes sociais que fundamentam o preconceito no futebol feminino em diferentes contextos. 
Quadro 1 - Sumário dos estudos revisados com seus objetivos e perspectivas de desenvolvimento

\begin{tabular}{|c|c|c|}
\hline AUTOR(ES) & OBJETIVO (S) & $\begin{array}{l}\text { PERSPECTIV ADA PESQUISA/PRINCIPAIS CONCLUSŌES/O QUE } \\
\text { FUNDAMENTA O PRECONCEITO? }\end{array}$ \\
\hline $\begin{array}{l}\text { 1. MOURÃO, } \\
2000\end{array}$ & $\begin{array}{l}\text {-Descrever a significação das represertações } \\
\text { sociais associadas à mulher brasileira ms } \\
\text { atividades físico-desportivas ertre } 1870 \text { e } 1950 \text {. }\end{array}$ & $\begin{array}{l}\text { Perspectiva histórica: Segregação que relegou as mulheres ao espaço dméstico } \\
\text { e à realização de atividads que ao exigis sem grande esforço físico. } \\
\text { O que fundamenta? Sociedade patriarcal, valores higienistas e eugenistas, a falta } \\
\text { de interesse da mulher. }\end{array}$ \\
\hline $\begin{array}{l}\text { 2. DARIDO; } \\
\text { SOUZA } \\
\text { JÚNIOR, } 2002\end{array}$ & $\begin{array}{l}\text {-Verificar o desenwolvimento das aulas de } \\
\text { Educação Fisica quarto ao gênero, qual a } \\
\text { aderências das meninas à prática do futebol e a } \\
\text { preferência desta modalidade comparada ao } \\
\text { basquetebol, voleibol e handebol e como se dá a } \\
\text { ocupação dos espaços esportivos esco kares com } \\
\text { relaçâo ao gêner a }\end{array}$ & $\begin{array}{l}\text { Perspectiva pedagógica: } \mathrm{O} \text { esporte utilizado na escoha como for ma de } \\
\text { discriminar. A falta de preparaçâo dos profis sio mis de EF reproduz o preconceito } \\
\text { de gênero nas escolas. } \\
O \text { que fundamenta? Idéa de sexo frágil }\end{array}$ \\
\hline $\begin{array}{l}\text { 3. DARIDO, } \\
2002\end{array}$ & $\begin{array}{l}\text {-Anal isar as discriminações e preconceitos } \\
\text { associados à questão de gênero, a partir da prática } \\
\text { de fute bol feminino no Brasil; } \\
\text {-Comprender as razões para o início tardio da } \\
\text { participação feminina noesporte nopaís. }\end{array}$ & $\begin{array}{l}\text { Perspectiva h is tórico-ped agógica: Exclusão da mulher da prática do es porte; } \\
\text { O que fundamenta? Idéia de que o feminino é um desvio construído a partir do } \\
\text { masculino (infer ioridade femin ina), temor da masculinzzação da mulher. }\end{array}$ \\
\hline $\begin{array}{l}\text { 4. GOELLNER, } \\
2003\end{array}$ & -A nal isar a inserç̃o das brasileir as no futebol. & $\begin{array}{l}\text { Perspectiva histórica: Controle estatal do corpo feminino. Atualmente, } \\
\text { espetacularização do corpo feminino, transgressão da mturalidade sexual } \\
\text { feminina } \\
\text { O que fundamenta? Temor da masculinização da mulher e modificação de sua } \\
\text { moral. }\end{array}$ \\
\hline $\begin{array}{l}\text { 5. RIGO et al, } \\
2005\end{array}$ & $\begin{array}{l}\text {-Anal isar duar pesquisas so be as memór ias do } \\
\text { esporte pelotense referentes ao futebol feminino e à } \\
\text { participação das mulheres na natação local. }\end{array}$ & $\begin{array}{l}\text { Perspectiva histórica: Cerceamerto da mulher em determinadas modalidades } \\
\text { esportivas (proibição dos jogos másculo s). Es petacul ai ząãa do corpo femi nino } \\
\text { (us o da beleza para atrair o público). } \\
\text { O que fundamenta? Mito do sexo frágil e melhoria da raça. }\end{array}$ \\
\hline $\begin{array}{l}\text { 6. FRANZINI, } \\
2005\end{array}$ & $\begin{array}{l}\text {-Anal isar as leituras sobre a presença do sexo } \\
\text { feminino dentro e fora dos gramados durante a } \\
\text { primeira metade do sécub XX; } \\
\text {-Discutir as formas de irtegraçao permitidas às } \\
\text { mulheres, suas manifestações proibidas e seus } \\
\text { significados. }\end{array}$ & $\begin{array}{l}\text { Perspectiva h is tórica: Segregação da mulher a ambiente domético. Criąão de } \\
\text { leis e propaga nas cortra o futebol feminim. } \\
\text { O que fundamenta? Hipótese do futebol enquanto espaço masculino. A entrada } \\
\text { da mu lher no futebol como subversão da virilidade e inversão social da } \\
\text { hegemonia social masculina. }\end{array}$ \\
\hline $\begin{array}{l}\text { 7. MOURĀO; } \\
\text { MOREL } 2005\end{array}$ & $\begin{array}{l}\text {-Analisar o discurso da mídia inpressa sobre o } \\
\text { futebol feminino no período de } 1930 \text { a } 2000 .\end{array}$ & $\begin{array}{l}\text { Perspectiva histórica: Futebol feminino como diver timento, espetáculo de } \\
\text { inabilidide e comédia Atualmente a visibilidade é concedida às jogadoras que } \\
\text { comprovam fe minilidade através da beleza e maternidade. } \\
\text { O que fundamenta? Futebol como pratica masculina Erotzação da mulher. }\end{array}$ \\
\hline $\begin{array}{l}\text { 8. AZZA RITO et } \\
\text { al, } 2006\end{array}$ & $\begin{array}{l}\text {-Examinar as for ma de particip ação e de resistênia } \\
\text { ao preconceito de gênero nas auks de EF. }\end{array}$ & $\begin{array}{l}\text { Perspectiva pedagógica pós-estruturalista: Competitividade ms relações de } \\
\text { gênero durante as aulas de EF, opres são dento e fora da escola. } \\
\text { O que fund amenta? Crença num po der natural do gênero mas culim em relação } \\
\text { à prática esportiva. }\end{array}$ \\
\hline $\begin{array}{l}\text { 9. BORGES et } \\
\text { al, } 2006\end{array}$ & $\begin{array}{l}\text {-Investigar o compo rtamentor esiliente em meninas } \\
\text { que } p \text { aticam o futeb } 1 \text {. }\end{array}$ & $\begin{array}{l}\text { Perspectiva p sicos social: Segregação, ridicularização, exclus̃̃o. Determinismo } \\
\text { das funções sockais por gênero. Desencorajamento da mulher na participação } \\
\text { esportiva. } \\
\text { O que fundamenta? Idéa de incompetência e fragilidade. }\end{array}$ \\
\hline 10. VIA NA, 2008 & $\begin{array}{l}\text {-Anal isar a construção cultural do corpo feminino e } \\
\text { verific ar os preconceitos associados às questões de } \\
\text { gênero no futebol brasileiro. }\end{array}$ & $\begin{array}{l}\text { Perspectiva pedagógica: Falta de incentivo para o esporte, mulheres } \\
\text { clas sificadas como inábeis. } \\
\text { O que fundamenta? Aconstrução social da fragilidade feminina. }\end{array}$ \\
\hline $\begin{array}{l}11 . \\
\text { CHALABAEV et } \\
\text { al, } 2008\end{array}$ & $\begin{array}{l}\text {-Examinar os efeitos de estereótipos de gênero na } \\
\text { performance de jogadoras de futebo } \mathrm{L}\end{array}$ & $\begin{array}{l}\text { Perspectiva social: Preconceito e crítica em rehação à mu lher que joga futebol. } \\
\text { O que findamenta? Idéia de que as mu lheres têm habilidades fracas para o } \\
\text { futebol. }\end{array}$ \\
\hline $\begin{array}{l}\text { 12. RIGO et al., } \\
2008\end{array}$ & $\begin{array}{l}\text {-Contribu ir para a historiografia do fute bol } \\
\text { feminino investigando o caso peloterse em } 1950 \text {. }\end{array}$ & $\begin{array}{l}\text { Perspectiva histórica: Proibição do futebol feminino, necessidade de controhar o } \\
\text { corpo feminino. } \\
\text { O que fundamenta? Mito do sexo frágil e temor da autonomia feminina }\end{array}$ \\
\hline $\begin{array}{l}\text { 13. CRUZ; } \\
\text { PALMEIRA, } \\
2009\end{array}$ & $\begin{array}{l}\text {-Anal isar as cortribuições da EF no processo de } \\
\text { construção de identidade de gênero. }\end{array}$ & $\begin{array}{l}\text { Perspectiva pedagógica: Reprodução de ester eótipos sexuais na escola } \\
\text { Expropriação do direito de praticar esportes. } \\
\text { O que fundamenta? Mito do sexo fágil e melhor ia da raça, diferenças } \\
\text { bioló gicasentre gêneros. }\end{array}$ \\
\hline $\begin{array}{l}\text { 14. BATISTA; } \\
\text { DEVIDE, } 2009\end{array}$ & $\begin{array}{l}\text {-Analisar a inserção das mulheres no futebol } \\
\text { brasileiro e o papel da mídia esportiva nesse } \\
\text { processo. }\end{array}$ & $\begin{array}{l}\text { Perspectiva h is tórica: Falta de visibilidade, erotização do corpo feninino. } \\
\text { o que fundamenta? Mas culinização das mulheres at letas, sociedade sexi sta e } \\
\text { patriarcal. }\end{array}$ \\
\hline
\end{tabular}

Antes de nos aprofundarmos na discussão das categorias e núcleos de sentido, realizamos uma descrição das pesquisas escolhidas procurando desenhar o perfil dos dados coletados e dos periódicos consultados. 
Dentre os 14 estudos selecionados, 11 deles foram publicados em periódicos nacionais Movimento, Motriz, Revista Brasileira de Educação Física e Esporte e Revista Brasileira de História ${ }^{3}$, enquanto apenas 3 (BATISTA; DEVIDE, 2009, CHALABAEV et al., 2006 e AZZARITO et al., 2006) foram publicados em periódicos internacionais. Estes periódicos são o EF Deportes, Research Quarterly for Exercise and Sport e o Journal of Sport \& Exercise Psychology, específicos da Educação Física. Ainda em relação à especificidade das áreas de conhecimento referentes aos periódicos pesquisados, vale ressaltar que apenas o estudo de Franzini (2005) não fora publicado em periódico da Educação Física.

Quanto à qualificação dos periódicos de origem, verificamos nas publicações nacionais um predomínio de revistas com qualis superior ao nível B1 $(\mathrm{n}=11)$ e algumas publicações em nível B5 ( $\mathrm{n}=2)$. Os periódicos internacionais Research Quarterly for Exercise and Sport e o Journal of Sport \& Exercise Psychology possuem qualis A2 e A1, respectivamente. A revista não indexada como específica da Educação Física possui nível A1.

No que diz respeito às temáticas, registramos uma distribuição dos trabalhos entre três abordagens principais: histórica, pedagógica e psicossocial. Cada uma destas abordagens revela as principais intenções e possibilidades de investigar o preconceito no futebol feminino, consideradas representativas para o recorte realizado por nós.

As diferentes perspectivas teóricas contempladas no corpus de trabalhos parecem revelar dois aspectos importantes. $\mathrm{O}$ primeiro refere-se ao reconhecimento do preconceito contra a mulher no esporte em diversos ambientes da sociedade como nas escolas, clubes e centros de reintegração social (MOURÃO, 2000; BORGES et al., 2006). O segundo aspecto é o da quantidade de estudos históricos que visam identificar as raízes do preconceito de gênero no âmbito esportivo, ou que pelo menos apontam para razões

\footnotetext{
${ }^{3}$ Selecionamos apenas periódicos de nível igual ou superior a B5 seguindo as determinações da Coordenação de Aperfeiçoamento de Pessoal de Nível Superior (CAPES).
} 
históricas que fundamentam o preconceito no futebol feminino (GOELLNER, 2003, MOURÃO; MOREL, 2005; RIGO et al., 2008).

Estes elementos levam-nos a considerar a necessidade de conduzir nossa discussão abordando as diversas formas de proibição, segregação e discriminação, que remetem a nosso entendimento de preconceito, ao mesmo tempo em que nos parece crucial considerar a leitura histórica de nosso objeto. Ou seja, reiteramos a necessidade de investigar as formas de manifestação do preconceito, bem como averiguar seus aspectos genealógicos, pois, como nos diz Foucault (2006), em certa medida, toda forma de controle da sexualidade responde às intenções de utilização econômica criadas intencionalmente para determinar as nossas formas de viver.

No próximo momento prosseguimos na discussão dos resultados tentando revelar o preconceito no futebol feminino à luz das teorias constituintes de cada artigo, para depois identificar as bases sócioculturais do preconceito. Adiantamos que a estruturação argumentativa segue a lógica das perspectivas identificadas na interpretação dos textos, isto é, obedece à tríade histórica, pedagógica e psicossocial.

\subsection{PeRspectiva históRICA do PRECONCEITO NO FUteBOL FEMININO BRASILEIRO}

Uma parte significativa dos estudos identificados $(n=8)$ apresenta análises históricas sobre a participação feminina no contexto esportivo utilizando o caso do futebol para demonstrar os preconceitos que as mulheres tiveram de superar para obter reconhecimento social.

Nesse sentido, dois grupos de estudos podem ser vislumbrados: estudos que focalizam as representações sociais da participação da mulher no contexto esportivo, e estudos de base genealógica que abordam os problemas da inserção da mulher no futebol e suas ressonâncias na atualidade. 
No conjunto dos artigos que seguem a primeira abordagem, alguns autores sustentam a importância de se estudar a história do futebol feminino como forma de compreender as formas de aceitação da mulher em espaços públicos da sociedade. Podemos citar como exemplos os estudos de Mourão (2000) e Rigo et al. (2005) e Rigo et al. (2008) os quais abordam o higienismo e a eugenia, bem como a proibição oficial do futebol feminino na ditadura estadonovista, como determinantes sócio-históricas que promoveram diferentes formas de dominar o corpo feminino no contexto esportivo.

Ao defender a tese de que a participação esportiva da mulher transitou - e ainda transita - da segregação para a democratização, Mourão (2000) afirma que a inserção progressiva da mulher nos esportes se deu de maneira sutil e suave. Apesar da significativa participação feminina no esporte, é possível notar sinais de um modelo esportivo pensado para as mulheres. No caso da eugenia, por exemplo, longe de haver uma proibição, as mulheres foram estimuladas a participar de certos tipos de esporte que assegurassem boa saúde e disposição.

O movimento de eugenia da raça, dos anos 30 , incrementou a participação das mulheres no esporte de forma mais explícita, pois vários já eram os espaços esportivos femininos em diferentes modalidades pelas cidades do Brasil. O exercício era um dos instrumentos utilizados para a formação de uma mulher mais forte, para a função da reprodução de uma sociedade eugênica (MOURÃO, 2000, p. 15).

Assegurar a prática esportiva representou, por outro lado, a circunscrição de certas práticas legitimamente femininas, como o vôlei, a dança, a ginástica. Logicamente, este quadro suscitou o reconhecimento dos esportes vigorosos como exclusivos dos homens, considerados naturalmente aptos para realizar esforço que exigem vigor físico.

Rigo et al. (2005; 2008), apresentando uma leitura semelhante, mas, remetendo ao caso de Pelotas-RS, demonstram que o processo histórico de aceitação da mulher no esporte corroborou para a atual 
erotização do corpo esportivo feminino. Para os autores, o processo de erotização do corpo ativo feminino funcionou como movimento de entrada e consolidação da mulher atleta no campo esportivo.

Ao coletarmos os depoimentos, observamos a ressalva de nossas entrevistadas em relação às competições esportivas femininas por elas apresentadas como espaços nos quais era possível visualizar a mulher atleta como um ser capaz de congregar beleza, graça, corpos delineados, força e virilidade sem se tornar masculinizada, mas ressaltando, ao invés disso, sua feminilidade (RIGO et al., 2005, p. 141).

Os exemplos da erotização e da criação de atividades físicas controladas segundo as limitações biológicas da mulher não revelam apenas detalhes dos diferentes momentos históricos do esporte feminino. Revelam também um quadro histórico de disputas que põe em xeque certos posicionamentos pré-concebidos sobre a passividade da mulher na história. Conforme afirmam Rigo et al. (2005) e Mourão (2000), o fator decisivo para a construção do atual horizonte esportivo feminino foi a vontade e o interesse da mulher em exercer sua motricidade como um direito.

Não obstante, o preconceito analisado sob a lente histórica revela aproximações com argumentos científicos que lhe concederam força. É sobre a construção de argumentos que buscaram comprovar a inferioridade feminina para a prática esportiva que o segundo grupo de estudos históricos pode ser destacado no corpus das obras analisadas.

Interpretações históricas do preconceito no contexto esportivo, para além de tentar desvendar as condições do atual futebol feminino, parecem se centrar nos movimentos históricos de dominação do corpo da mulher. Estudos como os de Darido (2002), Goellner (2003) e Franzini (2005) demonstram a presença de argumentos científicos e legais produzidos para, primeiramente ratificar a presença feminina no ambiente doméstico, e, num segundo momento, usar o movimento humano como forma de maximizar as funções maternais e reprodutoras da mulher. 
Dentre estes argumentos, destacamos a criação do mito do sexo frágil o qual é, ainda hoje, determinante para reprodução de condutas sexistas que discriminam a participação feminina em certos âmbitos sociais. A origem deste mito remete aos últimos três séculos, quando o uso político do corpo humano serviu de base para a construção de um dispositivo econômico da sexualidade fundado na idéia da mulher frágil, mãe de família e senhora da casa, e homem forte trabalhador e dono dos espaços públicos (MARTIN, 2006).

Encontrando base em argumentos supostamente científicos, o mito do sexo frágil contribuiu historicamente para controlar as práticas corporais desempenhadas pelas mulheres. Na história do Brasil, exatamente na transição entre os séculos XIX e XX, destacam-se os esforços para impedir a participação da mulher no campo das práticas esportivas. Conforme afirma Goellner (2003), as desconfianças em relação à presença da mulher no esporte estiveram culturalmente associadas ao medo de vulgarizar o corpo feminino, ou seja, de torná-lo masculino por meio do esforço físico intenso.

Particularmente, em relação ao futebol feminino, pode-se considerar que o mito do sexo frágil atuou como obstáculo ao consolidar a crença de que o esforço físico seria inapropriado para proteger a feminilidade da mulher "normal". De acordo com Franzini (2005), o mito do sexo frágil sustentou um forte movimento contrário à aceitação do futebol como prática desportiva feminina. Utilizandose de leis e propagandas, buscou-se desacreditar o futebol considerando-o inadequado à delicadeza. Na verdade, as mulheres eram consideradas incapazes de se adequar às múltiplas dificuldades do "esporte-rei". Para o autor, a insensibilidade em relação ao "futebol de saias" desencadeou um processo que ainda está em andamento:

Hoje, passado mais de meio século da perseguição promovida pela ditadura estadonovista, a identidade masculina criada e constantemente reafirmada ao longo da história da bola no Brasil faz com que boa parte das mulheres sequer se reconheça no jogo "coisa de homem", lembremos; ao mesmo tempo, outras enfrentam dificuldades de toda sorte para 
tentar se afirmar dentro dos gramados, com a bola nos pés. Seja como for, para todas elas o país do futebol assume forma bem diversa daquela consagrada no senso comum: para as primeiras, tal país é um lugar muito distante; para as demais, um lugar de exílio (FRANZINI, 2005, p. 325).

Em relação à história do preconceito no futebol feminino, é possível comentar mais detalhadamente sobre a sua genealogia, ao mesmo tempo em que descobrimos, nos próprios artigos, quais dificuldades se mostram significativas na atualidade. A partir dos estudos de Mourão e Morel (2005) e de Rigo et al. (2008), é possível entender que a mídia teve um papel importante dos mecanismos de exibição do corpo atlético feminino, que precisa ser forte sem perder sua feminilidade. A relação entre interdição do corpo feminino e a prática do futebol se faz mais uma vez presente, entretanto, sobre a ótica da aparência feminina normalizada. Esta imagem normalizada da "mulher feminina" se insere no conjunto de aspectos discriminatórios que continuam a dificultar a consolidação do futebol feminino, pois, através dela se perpetua a idéia de que o espaço do futebol não é tipicamente feminino. Nesse sentido, Rigo et al. (2008, p. 185) afirma que

\begin{abstract}
Apesar de o futebol feminino brasileiro ter deixado de ser alvo de interdição, sua consolidação continua sendo um desafio. Boa parte da discriminação e dos preconceitos que ele continua enfrentando, certamente, tem a ver com os 30 anos de proibição e de desqualificação que ajudaram a construir uma moral sexista alicerçada no discurso de que mulher não combina com futebol.
\end{abstract}

Mas, a mídia não se refere apenas à aparência da mulher que joga. Ela se refere também ao espetáculo esportivo e à "espetacularização" do corpo feminino que, no contexto do futebol, passou a ser representado como "comédia", "divertimento", "espetáculo de inabilidade" e "caricatura". A partir do texto de Mourão e Morel (2005), podemos visualizar um controle histórico-estético do futebol feminino que flutua entre a exibição de corpos atléticos 
femininos e normalizados, e a aceitação do futebol feminino como espetáculo caricatural, versão imperfeita e ridícula do futebol masculino, que seria "perfeito" tecnicamente.

Finalizando a reflexão sobre a história do preconceito no futebol feminino percebemos, à luz dos artigos, que as mulheres passaram por processos históricos de segregação, política de controle legal e biológico, e estigmatização do corpo feminino enquanto frágil, incapaz e delicado.

Esta problemática contribuiu para reproduzir na atualidade novas formas de preconceitos relacionadas à erotização, espetacularização e agenciamento da beleza feminina no esporte, e à crença de que a natureza feminina é qualitativamente inferior. Vale ressaltar o controle exercido sobre a visibilidade do futebol feminino, pois, segundo Mourão e Morel (2005) e Batista e Devide (2009), as jogadoras que comprovam sua feminilidade através da beleza ou da maternidade ocupam mais facilmente lugares privilegiados na mídia e na sociedade.

\subsection{PeRspectiva PEDAgógicA: PRECONCEITO E FUteBOL FEMININO NA ESCOLA}

O segundo grupo de estudos sobre o preconceito no futebol feminino remete às relações de poder e ao preconceito de gênero no ambiente escolar $(\mathrm{N}=5)$. Possuindo um caráter pedagógico estes estudos procuram analisar como se dão os conflitos de gênero nas aulas de Educação Física e a contribuição da Educação Física no processo de construção de identidades de gênero.

As investigações de Souza Júnior e Darido (2002) e Azzarito et al. (2006) remetem ao desenvolvimento das relações de gênero nas aulas de Educação Física considerando que estas relações são sempre conflitantes, uma vez que, o espaço de exercício físico é entendido socialmente como masculino.

Souza Júnior e Darido (2002), ao analisar a aderência das meninas nas aulas de Educação Física, perceberam que os meninos ainda dominam amplamente os espaços destinados à prática esportiva, especificamente o futebol na escola. Depois de entrevistar 70 alunas 
da sétima série de Rio Claro-SP, os autores constataram que 88,57\% das alunas acreditam que os meninos dominam o espaço do esporte na escola.

Quanto à preferência esportiva das meninas participantes do estudo, observa-se que o voleibol $(53,52 \%)$ aparece como o esporte predileto, seguido pelo futebol $(39,43 \%)$, havendo uma grande diferença entre estes dois e o handebol $(4,22 \%)$ e o basquetebol $(2,81 \%)$. A partir destes resultados, os autores concluem que a perpetuação da separação entre meninos e meninas nas aulas parece estar ligada à falta de preparação dos profissionais de Educação Física. Sendo assim,

[...] os programas de formação profissional devem estar atentos a estas problemáticas, incentivando e desenvolvendo, já na graduação, propostas de trabalho que envolvam a implementação e a discussão efetiva da coeducação. Deste modo os futuros professores passariam a conhecer as dificuldades e vantagens deste tipo de trabalho, podendo refletir e construir estratégias que efetivamente mostrem-se eficazes na sua prática (SOUZA JÚNIOR; DARIDO, 2002, p. 08).

Examinando as formas de participação e de resistência ao preconceito de gênero nas aulas de Educação Física, Azzarito et al. (2006) percebem uma limitação das meninas na escolha das práticas corporais esportivas durante as aulas de educação física. Esta limitação ocorre devido à competitividade dos meninos e às relações de opressão e agressão que ocorrem dentro e fora da escola.

Assim como Souza Júnior e Darido (2002), Azzarito et al. (2006) percebe que as meninas gostam de jogar futebol, entretanto, as condições de agressividade, impostas geralmente pelos próprios meninos, contribuem para o desinteresse de sua prática. Além disso, o espaço do futebol é entendido como espaço exclusivo para formação da masculinidade. Este aspecto ratifica a crença na mulher como sexo frágil e na existência de uma vantagem biológica dos meninos na prática do futebol. 
Insistindo no contexto pedagógico, Viana (2008) e Cruz e Palmeira (2009) analisam a construção cultural do gênero a partir das relações de preconceito. O estudo de Viana (2008) foi bibliográfico e abordou aspectos gerais da prática do futebol, enquanto que Cruz e Palmeira (2009) realizaram um estudo etnográfico numa escola de Guanambi-BA.

Concordando com Souza Júnior e Darido (2002) e Azzarito et al. (2006), Viana (2008) considera que o preconceito no futebol feminino realizado na escola é em grande medida reforçado pelos professores que não incentivam as meninas a participar das aulas. Isso representa uma contribuição direta da Educação Física para concretizar o mito da fragilidade feminina.

As meninas não possuem incentivo para o esporte durante a infância, não jogam bola, não sobem em árvores, não correm, ou seja, não realizam quando pequenas nenhuma atividade que beneficiará sua inserção ao esporte. Basta observar os brinquedos e as brincadeiras que permeiam a infância feminina fazendo com que a sociedade as identifique como fracas e inábeis ao esporte, principalmente no futebol (VIANA, 2008, p. 645).

Nesta linha argumentativa, Cruz e Palmeira (2009) denunciam como a escola pode contribuir para formação de sujeitos que reproduzem condutas sexistas. Nas aulas de Educação Física, especificamente, os autores perceberam uma expropriação do direito feminino de jogar futebol.

O processo de transmissão dos preconceitos sexuais baseia-se na maioria das vezes, em argumentos de ordem biológica, o que os torna naturais e imutáveis, o que por sua vez, desencadeia numa diferença acentuada de experiências vividas por meninos e meninas, interferindo diretamente na sua vida social (CRUZ; PALMEIRA, 2009, p. 130).

É possível perceber que o preconceito de gênero nas escolas reflete relações de poder estabelecidas na sociedade. Quando os professores de Educação Física não problematizam pedagogicamente o preconceito em suas aulas, corre-se o risco de fortalecer tendências sexistas. 
Ressaltamos, finalmente, que o princípio que fundamenta o preconceito nas aulas de Educação Física é ainda a idéia do sexo frágil associada à crença do futebol como espaço ritual e mítico da masculinidade. A forte presença do argumento biológico como forma de preconceito nas aulas de Educação Física pode ser um efeito da herança da área, historicamente vinculada à maximização das capacidades físicas com fins capitalistas e biopolíticos. Por outro lado, a grande referência às determinantes biológicas nos estudos pode ser um reflexo epistemológico dos estudos que se propõem a investigar as relações de dominação de gênero, como exemplifica Lovisolo, Soares e Bartholo (2006).

\subsection{Perspectiva psicossocial do PRECONCEITO NO FUteBOL FEMININO}

Apesar de todos os estudos revelarem implicações sociais do preconceito no futebol feminino, dois artigos parecem caracterizar um núcleo temático referente aos aspectos psicossociais do preconceito. Esta classificação se justifica pela atenção concedida à discriminação e seu papel como modulador da vida em sociedade. Ou seja, os artigos tratam diretamente dos efeitos que o preconceito pode desencadear nas formas de atuação dos sujeitos na sociedade.

Borges et al. (2006) verificam o uso do futebol feminino num programa de inclusão social em Viçosa-MG. Através de um estudo etnográfico, os autores perceberam que o futebol pode ser utilizado como forma de resistir a diversas formas de preconceito de gênero. Mesmo considerando esta possibilidade, o futebol feminino é palco para diferentes tipos de preconceito que vão desde a segregação à ridicularização.

O estudo aponta que o desencorajamento da mulher em relação ao futebol tem como principal causa um determinismo biológico das funções sociais por gênero, que pode ser retratado mais uma vez pelo mito do sexo frágil.

No contexto esportivo, Chalabaev et al. (2006) apontam que o preconceito associado a estereótipos de incompetência e fragilidade atuam negativamente na performance atlética das mulheres. A 
alteração psicológica mais substancial é a acentuação da capacidade de avaliar os resultados, fato que implica numa supervalorização dos erros em detrimento dos acertos obtidos. Nesse sentido, os pesquisadores reiteram que o uso de estereótipos pode afetar a vida dos sujeitos das formas mais variadas.

A partir destes dois estudos pode-se vislumbrar que o preconceito sobre as mulheres é causado pela idéia de incompetência e fragilidade, as quais mais uma vez se fundamentam no discurso da diferença biológica entre os gêneros.

\section{Conclusão}

A análise dos estudos permitiu construir um quadro teórico do preconceito no futebol feminino. Pudemos perceber que as diversas manifestações de preconceito têm raízes históricas e culturais. É possível perceber também que as condutas sexistas no esporte são ressonâncias de nossa estrutura social dicotomizada em relação ao gênero.

Em relação aos nossos objetivos, identificamos que as formas de preconceito mais evidentes no contexto do futebol feminino são a segregação, a exclusão, o cerceamento da mulher em determinadas práticas esportivas consideradas femininas, limitação na escolha das práticas esportivas, erotização do corpo feminino e vigilância sobre a identidade de gênero das atletas.

Os aspectos sócio-culturais que fundamentam estas formas de preconceito são o mito do sexo frágil, e as ideais de incapacidade e incompetência atlética feminina. $\mathrm{O}$ controle biológico da aparência corporal da mulher pode ser apontado como o argumento mais utilizado para proibir o desencorajar a participação feminina no futebol.

Concluímos que a investigação sobre o preconceito no futebol feminino carece de estudos de campo que possibilitem abordar mais profundamente questões específicas de diferentes realidades sociais. 
Tais estudos poderão auxiliar na realização de futuras pesquisas preocupadas em descrever as dificuldades enfrentadas, ou de debater as questões epistemológicas mais ocultas na problemática. 

Prejudice in women's brazilian soccer: a
systematic review

Abstract: The objective of this study is to identify the conditions of existence of gender prejudice in the context of women's football on science literature and discuss the socio-cultural aspects which it is based. For this we performed a search for articles in databases using specific key-words. We founded three main approaches in the collected articles: historical, educational and psychosocial. The main forms of prejudice about women's football is the segregation, the restriction of women in certain sports considered female, eroticism of the female body and surveillance on the gender identity of the athletes.

Key words: Female soccer, Prejudice, Gender identity

\section{Prejuicios en fútbol femenino brasileño: una} revisión sistemática

Resumen: El objetivo de este estudio es identificar las condiciones de existencia en de prejuicios de género en el contexto del fútbol femenino en la literatura científica y discutir los aspectos socio-culturales que se basa. Se realizó una búsqueda de artículos en bases de datos utilizando descriptores específicos. Se registró una distribución de trabajos entre tres principales enfoques: histórico, educativo y psicosocial. Las principales formas de prejuicios sobre el fútbol femenino es la segregación, la restricción de las mujeres en ciertos deportes considerados femeninos, erotismo del cuerpo femenino y la vigilancia sobre la identidad de género de los atletas.

Palabras-clave: Fútbol femenino, Prejuicio, Identidad de género

\section{REFERÊNCIAS}

ALMEIDA, M.; PALMA, A. Efeito da idade relativa no futebol feminino: análise da copa do mundo sub-17, da FIFA. Revista Arquivos em Movimento, Rio de Janeiro, v. 7, n. 1, p. 21-33, jan./jun. 2011. 
AZZARITO, L., et al. If I had a choice, I would. A feminist poststructuralist perspective on girls in physical education. Research Quarterly for Exercise and Sport, Corvallis, v. 77, n. 2, p. 222-239, june 2006.

BATISTA, R.; DEVIDE, F. Mulheres, futebol e gênero: reflexões sobre a participação feminina numa área de reserva masculina. EFDeportes.com, Buenos Aires, v. 14, n 137, 2009. Disponível em: <http://www.efdeportes.com/efd137/mulheresfutebol-e-genero.htm>. Acesso em: 20 jul. 2012.

BORGES, C. N. et al. Resiliência: uma possibilidade de adesão e permanência na prática do futebol feminino. Movimento, Porto Alegre, v. 12, n. 1, p. 105-131, jan./ abr. 2006.

BOURDIEU, Pierre. O poder simbólico. Rio de Janeiro: Bertrand Brasil, 2007

CHALABAEV, A. et al. Do Achievement Goals Mediate Stereotype Threat? An Investigation on Females' Soccer Performance, Journal of Sport and Exercise Psychology, Tallahassee, v. 30, n. 2, p. 143-158, apr. 2008.

CRUZ, M.; PALMEIRA F. Construção de identidade de gênero na educação física escolar. Motriz, Rio Claro, v.15, n.1 p.116-131, jan./mar. 2009.

DARIDO, S. C. Futebol feminino no Brasil: do seu início à prática pedagógica. Motriz, Rio Claro, v. 8, n. 2, p. 6-15, 2002.

EDWARDS, L.; JONES, C. Critical reflections postmodernism, queer theory and moral judgment in sport: some critical reflections. International Review for the Sociology of Sport, n. 44, v. 331, 2009.

FARIA JÚNIOR, A. G. Futebol, Questões de Gênero e Coeducação: algumas considerações didáticas sob enfoque multicultural. Revista do Núcleo de Sociologia do Futebol, Rio de Janeiro, n. 2, 1995.

FOUCAULT, M. A história da sexualidade I: a vontade de saber. São Paulo: Graal, 2006.

FRANZINI, F. Futebol é "coisa para macho"? Pequeno esboço para uma história das mulheres no país do futebol. Revista Brasileira de História, São Paulo, v. 25, n. 50, p. 315-328, 2005.

GIULIANI, P. Os movimentos de trabalhadoras e a sociedade brasileira. IN: DEL PRIORE, Mary (Org.). História das mulheres no Brasil. São Paulo: Contexto, 2007. p. 640-668.

GOELLNER, S. V. Mulheres e futebol no Brasil: entre sombras e visibilidades. Revista Brasileira de Educação Física e Esporte, São Paulo, v. 19, n. 2, p. 14351, abr./jun. 2003. 
JAEGER, A. A. Gênero, mulheres e esporte. Movimento, Porto Alegre, v. 12, n. 1, p. 199-210, jan./abr. 2006.

LOVISOLO, H.; SOARES, A. J.; BARTHOLO, T. L. Feministas, mulheres e esporte: questões metodológicas. Movimento, Porto Alegre, v. 12, n. 3, p. 165-191, set./ dez. 2006.

MARTIN, E. A mulher no corpo: uma análise cultural da reprodução. Rio de Janeiro: Garamond, 2006.

MOURÃO, L. Representação social da mulher brasileira nas atividades físicodesportivas: da segregação à democratização. Movimento, Porto Alegre, n. 13, p. $05-18,2000 / 2$.

MOURÃO, L.; MOREL, M. As narrativas sobre o futebol feminino: o discurso da mídia impressa em campo. Revista Brasileira de Ciências do Esporte, Campinas, v. 26, p. 73-86, 2005.

MULROW, C. D. Systematic reviews: rationale for systematic reviews. BMJ, London, n. 309, p. 597-599, sept. 1994.

OLIVEIRA, S. R. et al. Futebol feminino de competição: uma análise das tendências do comportamento das mulheres. Revista Brasileira de Educação Física e Esporte, São Paulo, v. 20, n. 3, p. 209-218, jul./set. 2006.

QUEIROGA, M. et al. Somatotipo como indicador de desempenho em atletas de futsal feminino. Revista Brasileira Cineantropometria Desempenho Humano, v. 10, n. 1, p. 56-61, 2008.

RAGO, M. Trabalho Feminino e Sexualidade. História das mulheres no Brasil. IN: PRIORE, Mary Del (Org.). História das Mulheres no Brasil. São Paulo: Contexto, 2007, p. 578-606.

RIGO, L. et al. Memórias de corpos esportivizados: a natação feminina e o futebol infame. Movimento, Porto Alegre, v. 11, n.2, maio/ago. 2005.

RIGO, L. et al. Notas acerca do futebol feminino pelotense em 1950: um estudo genealógico. Revista Brasileira Ciência do Esporte, v. 29, n. 3, maio 2008.

SAMPAIO R.F.; MANCINI M.C. Estudos de revisão sistemática: um guia para síntese criteriosa da evidência científica. Revista Brasileira de Fisioterapia, São Carlos, v. 11, n. 1, jan./fev. 2007.

SILVA P.; ROMANO A.; ROXO C. Características fisiológicas, músculo- esqueléticas, antropométricas e oftalmológicas em jogadoras de futebol feminino consideradas de elite. Revista Brasileira de Medicina e Esporte, v.5, n.1, p.01-08, 1999.

SOUZA JÚNIOR, O. M.; DARIDO, S. A prática do futebol feminino no ensino fundamental. Motriz, Rio Claro, v. 08, n. 01, p.01-09, jan./abr. 2002. 
STEWIEN, E. T.; CAMARGO, O. P. Ocorrência de entorse e lesões do joelho em jogadores de futebol da cidade de Manaus, Amazonas. Acta ortopédica brasileira, v. 03, n. 13, p. 141-146, 2005.

VIANA S. Futebol: das questões de gênero à prática pedagógica, Conexões: revista da faculdade de Educação Física, Campinas, v. 06, ed. especial, p. 640648, jul. 2008.

Endereço para correspondência:

Rua Professor Júlio Ferreira de Melo, 916, apt. 502,

Boa Viagem

Recife/PE.

Recebido em: 25.07.2012

Aprovado em: 07.11.2012

Vovimento, Porto Alegre, v. 19, n. 01, p. 265-287, jan/mar de 2013. 